\title{
Rancangan Website E-CRM (Electronics Customer Relationship Management) Pada House Of Smith Pekanbaru
}

\author{
Radhi Adlan ${ }^{1}$, Wirta Agustin ${ }^{2}$, Yoyon Efendi ${ }^{3}$ \\ Jurusan Teknik Informatika, STMIK Amik Riau ${ }^{1,2,3}$ \\ radhiadlan@gmail.com ${ }^{1}$,wirtaagustin@stmik-amik-riau.ac.id ${ }^{2}$, yoyonefendi@stmik-amik-riau.ac.id ${ }^{3}$
}

\begin{tabular}{l}
\hline \hline Article Info \\
\hline History: \\
Dikirim 24 Juli 2018 \\
Direvisi 31 Agustus 2018 \\
Diterima 10 Desember 2018
\end{tabular}

Kata Kunci :

$C R M$

$E-C R M$

Website

\begin{abstract}
Abstrak
CRM (Customer Relationship Management) merupakan cara untuk pengelolaan relasi antara sebuah perusahaan didalam konsumsi produk atau jasa yang diproduksi perusahaan tersebut. Berkembangnya teknologi, metode CRM pun mulai dikembangkan menjadi Electronic Customer Relationship Management (E-CRM). Banyaknya varian produk yang ditawarkan oleh House of Smith dapat dimanfaatkan sebagai strategi unggulan dalam menjaga loyalitas pelanggan. Perancangan aplikasi E-CRM pada House of Smith adalah membantu perusahaan mengetahui kebutuhan pelanggan secara personal serta mampu memberikan pelayanan yang sesuai dengan karakter konsumen dan memberikan informasi yang dibutuhkan, sehingga perusahaan dapat mempertahankan pelanggan yang sudah ada dan mendapatkan pelanggan baru. Metode penelitian yang digunakan adalah observasi dan wawancara langsung ke House of Smith. Hasil dari analisa dan perancangan aplikasi E-CRM berbasis web ini adalah membantu House of Smith untuk memenuhi kebutuhan pelanggan guna meningkatkan kepuasan pelanggan sehingga tetap menjadi pelanggan setia. Aplikasi E-CRM ini merupakan alat interaksi yang menciptakan hubungan antara perusahaan dengan pelanggan menjadi lebih baik.
\end{abstract}

(C) This work is licensed under a Creative Commons AttributionShareAlike 4.0 International License.

\section{Koresponden:}

Wirta Agustin, Jurusan Teknik Informatika STMIK Amik Riau

Jl. Purwodadi Indah KM.10, Sidomulyo Barat, Tampan, Pekanbaru, Riau

E-mail : wirtaagustin@stmik-amik-riau.ac.id

\section{PENDAHULUAN}

CRM (Customer Relationship Management) merupakan cara untuk pengelolaan relasi antara sebuah perusahaan didalam konsumsi produk atau jasa yang diproduksi perusahaan tersebut. Berkembangnya teknologi, metode CRM pun mulai dikembangkan menjadi Electronic Costumer Relationship Management (E-CRM). Electronic Costumer Relationship Management (E-CRM) merupakan CRM yang melibatkan electronic serta berbasis online mode. Konsep E-CRM adalah pendekatan relevansi, contextual marketing communication yang nanti nya akan memantau perilaku pelanggan. Sehingga sangat cocok diterapkan pada perusahaan fashion atau perusahaan yang memiliki produk dengan nilai bersaing yang tinggi. Tujuan dari penataan dan pengelolaan 
menggunakan teknologi agar mampu menghasilkan informasi yang akurat, transparan, dan akuntabilitas serta bentuk profesionalisme dalam bekerja.

Konsep dari relationship marketing dasar pertama kali dikemukakan pada tahun 1983. Dari konsep hubungan pemasaran itulah terbangun CRM.Yang menjadi perbedaan utama hanyalah hubungan pemasaran yang kurang atau tidak menggunakan teknologi informasi. Sedangkan pada pengembangan CRM saat ini, seharusnya dilakukan dengan memperhatikan aspek teknologi, yaitu sistem dan bahkan melalui Website[1]. CRM adalah proses menargetkan, memperoleh, bertransaksi, melayani, mempertahankan dan membangun hubungan jangka panjang dengan pelanggan[2].

House of Smith merupakan salah satu perusahaan yang bergerak dibidang fashion. Tidak hanya menjual pakaian saja, House of Smith memiliki berbagai macam koleksi diantaranya sandal, sepatu, tas, serta aksesoris. Banyaknya varian produk yang ditawarkan oleh House of Smith dapat dimanfaatkan sebagai strategi unggulan dalam menjaga loyalitas pelanggan. Penelitian ini bertujuan untuk membangun website house of smith Pekanbaru menggunakan metode E-CRM yang user friendly dan menarik agar memudahkan pelanggan dalam mengaksesnya, menjaring pelanggan baru dan mempertahankan pelanggan lama.

\section{METODE PENELITIAN}

Tahapan penelitian yang dilakukan dibagi atas beberapa tahapan, yaitu: Pengumpulan Data, Konsep Teori dan Perancangan Sistem.

\subsection{Pengumpulan Data}

Untuk mendapatkan data yang benar dan akurat, teknik pengumpulan data dilakukan dengan cara sebagai berikut :

1. Observasi

Observasi dilakukan dengan mengamati secara langsung dan spesifik aktifitas dan kegiatan yang dilakukan ditempat penelitian yang ada sekarang, sehingga dapat dianalisa fitur-fitur apa saja yang dibutuhkan.

2. Wawancara (Interview)

Wawancara dilakukan dengan bertanya langsung kepada Pemilik House of Smith, terkait penelitian untuk memperoleh data atau informasi.

3. Studi Pustaka

Mengumpulkan data dengan cara mencari dan mempelajari dari berbagai sumber yang berkaitan dengan masalah yang diteliti, baik dari internet, buku, jurnal ilmiah dan dari bacaan lain yang dapat dipertanggung jawabkan.

\subsection{Konsep Teori}

Teori yang digunakan dalam penelitian ini adalah :

\subsubsection{CRM (Customer Relationship Management)}

CRM (Customer Relationship Management) adalah strategi untuk membangun, mengelola, dan memperkuat hubungan perusahaan dengan pelanggan yang loyal agar dapat tercipta hubungan yang tahan lama. CRM harus merupakan pendekatan customer-centric berdasarkan pandangan pelanggan. Ruang lingkup penanganan pelanggandalam CRM harus bersifat personal karena setiap pelanggan merupakan entitas yang unik. Upaya tersebut dilakukan untuk mengidentifikasi dan memahami perbedaan kebutuhan, prefensi dan perilaku dari tiap pelanggan yang berbeda-beda [3].

Menurut [4] Manajemen Hubungan Pelanggan (Customer Relationship Management) adalah manajemen hubungan antara perusahaan dan pelanggan sehingga baik perusahaan maupun pelanggannya akan menerima nilai maksimum dari hubungan ini. Dukungan teknologi informasi telah terbukti mampu memberikan dukungan secara teknis sehingga dapat membantu perusahaan melayani pelanggan dengan jumlah yang banyak. Sekalipun tidak membutuhkan dana atau investasi yang tidak terlalu besar, namun diyakini tetap mempunyai manfaat yang sangat besar[5]. 
Tujuan CRM yang utama adalah mengelola dan me-manage pelanggan agar terjadi suatu hubungan yang baik antara perusahaan dan pelanggan[6].

CRM dapat diklasifikasikan ke dalam 3 jenis, yaitu [7], yaitu operasional CRM, analitis CRM, dan kolaboratif CRM.

\subsubsection{Analytical CRM}

Analytical CRM adalah proses analisis data-data yang diperoleh dari Operational CRM. Sekarang ini banyak perusahaan berusaha untuk lebih mengerti tentang pelanggan mereka dengan memberikan respon secara lebih baik dan mengantisipasi kebutuhan mereka. Namun, kebanyakan perusahaan berfokus untuk mengimplementasikan CRM hanya sebatas untuk mengetahui kebutuhan dan keluhan dari pelanggan, yang pada praktisnya hanya berkonsentrasi pada komponen operational dan collaborative CRM, sehingga analisis akan pemahaman dan pengenalan terhadap pelanggan belum optimal. Oleh sebab itu, komponen analytical CRM dibutuhkan untuk mengoptimalkan hubungan antara perusahaan dengan pelanggannya[8].

Menurut [9], Analitis CRM (analytical CRM) fokus pada menangkap, menyimpan, mengekstraksi (extracting), mengintegrasi, memproses, menginterpretasi, menyebarkan, menggunakan dan melaporkan data yang berhubungan dengan konsumen (customer-related data) untuk meningkatkan nilai konsumen dan perusahaan. Analitis CRM berpondasi pada informasi mengenai konsumen (customer-related).

\subsubsection{Electronic Customer Relationship Management (E-CRM)}

Penerapan teknologi dalam CRM merupakan respon terhadap perubahan-perubahan yang ada dalam dunia. Istilah E-CRM mulai digunakan pada pertengahan tahun 1990-an ketika pelanggan mulai menggunakan web browser, internet, dan touch point elektronik lainnya (e-mail, PDA, call centers, dan lain-lain). E-CRM merupakan pengembangan dari CRM yang dilakukan secara elektronik. Menurut Chaffey (2009), E-CRM memiliki definisi penggunaan teknologi komunikasi digital untuk memaksimalkan penjualan pada pelanggan dan mendorong penggunaan online service. Pada buku EMarketing Excellence, [10] mengatakan adapun cara membangun hubungan yang baik antara konsumen adalah menggunakan pendekatakan DRAMA pada E-CRM. DRAMA yaitu: Dialogue, Relevancy, Accuracy, Magic dan Access.

\subsection{Perancangan Sistem}

\subsubsection{Use Case Diagram}

Perancangan use case diagram berdasarkan kebutuhan sistem sesuai dengan aktornya adalah sebagai berikut. Gambar 1 menjelaskan bahwa user memiliki wewenang masing-masing dan untuk dapat menjalankan fungsi yang ada di dalam sistem. Berikut ini merupakan use case diagram untuk sistem ini.

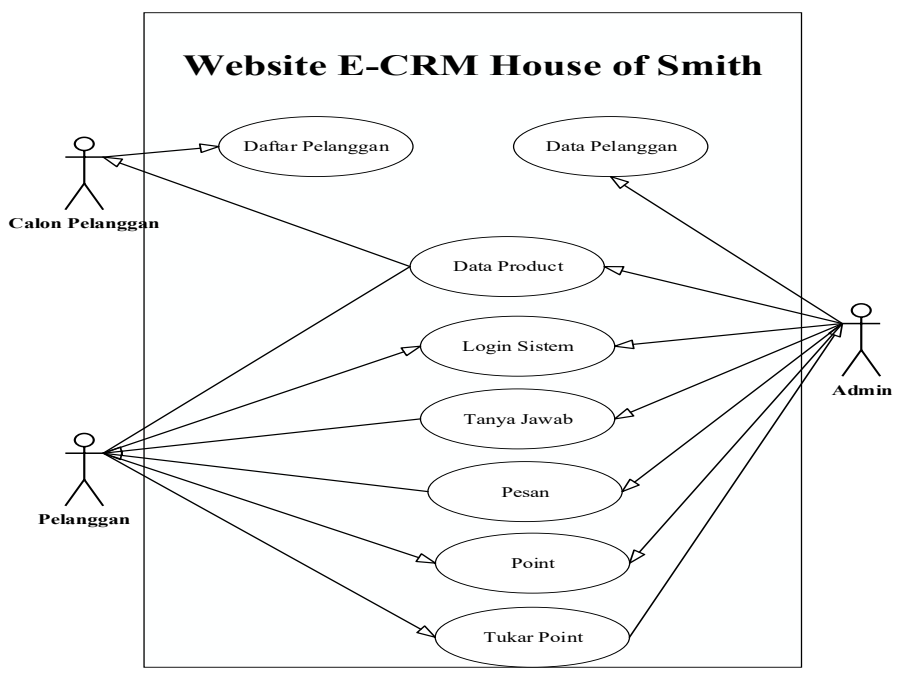

Gambar 1. Perancangan Use Case Diagram 
Berdasarkan perancangan use case diagram di atas adalah sebagai berikut:

Tabel 1. Skenario Use Case Login Sistem

\begin{tabular}{l|l}
\hline Use Case & Login Sisten \\
\hline Aktor & Admin, Pelanggan \\
\hline Pra Kondisi & Aktor ingin menggunakan sistem \\
\hline Paska Kondisi & Aktor telah masuk ke sistem \\
\hline Deskripsi & Aktor melakukan penggunaan sistem \\
\hline Aktor & Sistem \\
\hline $\begin{array}{l}\text { 1. Memasukan data username atau } \\
\text { email dan password }\end{array}$ & 2. Mengeksekusi data masukan \\
\hline
\end{tabular}

Proses pada tabel 1, aktor memasukan username atau email dan password kemudian sistem akan mengeksekusi data hasil inputan dan jika data yang dimasukan sesuai dengan data pada database akan menampilkan halaman utama.

Tabel 2. Skenario Use Case Daftar Pelanggan

\begin{tabular}{|c|c|c|}
\hline Use Case & \multicolumn{2}{|l|}{ Daftar Pelanggan } \\
\hline Aktor & \multicolumn{2}{|l|}{ Calon Pelanggan } \\
\hline Pra Kondisi & \multicolumn{2}{|c|}{ Aktor telah melihat form pendaftaran } \\
\hline Paska Kondisi & \multicolumn{2}{|c|}{ Aktor telah menginputkan data pelanggan } \\
\hline Deskripsi & \multicolumn{2}{|c|}{ Aktor daftar pelanggan sistem } \\
\hline \multicolumn{2}{|l|}{ Aktor } & Sistem \\
\hline \multicolumn{2}{|c|}{$\begin{array}{l}\text { 1. } \\
\text { Memilih menu pendaftaran } \\
\text { pelanggan }\end{array}$} & 2. Tampil halaman daftar pelanggan \\
\hline \multicolumn{3}{|c|}{ 3. Memasukan data pelanggan } \\
\hline & & $\begin{array}{l}\text { 4. Menampilkan hasil penginputan data } \\
\text { pelanggan }\end{array}$ \\
\hline 5. Login ke $\mathrm{s}$ & stem & \\
\hline
\end{tabular}

Proses pada tabel 2, aktor memilih menu pendaftaran pelanggan, lalu memasukan data pelanggan seperti nama, email, password dan informasi lainnya kemudian sistem akan melakukan penyimpanan kedalam database.

Tabel 3. Skenario Use Case Data Product

\begin{tabular}{|c|c|c|}
\hline Use Case & \multicolumn{2}{|l|}{ Data product } \\
\hline Aktor & \multicolumn{2}{|c|}{ Admin, Pelanggan, Calon Pelanggan } \\
\hline Pra Kondisi & \multicolumn{2}{|c|}{ Admin menginputkan data product } \\
\hline Paska Kondisi & \multicolumn{2}{|c|}{ Pelanggan dan calon pelanggan melihat data product } \\
\hline Deskripsi & \multicolumn{2}{|c|}{ Aktor mengelola data product } \\
\hline \multicolumn{2}{|l|}{ Aktor } & Sistem \\
\hline \multicolumn{2}{|c|}{ 1. Memilih menu product } & 2. Tampil halaman product \\
\hline \multicolumn{3}{|c|}{ 3. Memasukan data product } \\
\hline & & $\begin{array}{l}\text { 4. Menampilkan hasil penginputan data } \\
\text { product }\end{array}$ \\
\hline 5. Meliha & & \\
\hline
\end{tabular}

Proses pada tabel 3, aktor akan masuk ke menu product, lalu sistem akan menampilkan halaman data product dan bisa mengelola data product. Lalu para pelanggan dan calon pelanggan dapat melihat data product. 
Tabel 4. Skenario Use Case Tanya Jawab

\begin{tabular}{l|l}
\hline Use Case & Tanya Jawab \\
\hline Aktor & Admin, Pelanggan \\
\hline Pra Kondisi & Admin menginputkan pertanyaan dan beberapa jawaban \\
\hline Paska Kondisi & Pelanggan menjawab pertanyaan dari sistem \\
\hline Deskripsi & Proses ini digunakan untuk mengetahui kebutuhan pelanggan. \\
\hline
\end{tabular}

\begin{tabular}{c|c}
\hline Aktor & Sistem \\
\hline 1. Menginputkan data perrtanyaan & 2. Mengeksekusi data masukan \\
\hline 4. Melihat data pertanyaan & $3 . \quad$ Menampilkan data pertanyaan \\
\hline
\end{tabular}

Proses pada tabel 4, admin akan menginputkan data pertanyaan dan menginputkan beberapa jawaban dan feedback dari jawaban tersebut. Selanjutnya setiap pelanggan akan menjawab pertanyaan yang diajukan sistem tersebut.

Tabel 5. Skenario Use Case Mengelola Pesan

\begin{tabular}{l|l}
\hline Use Case & Mengelola Pesan \\
\hline Aktor & Admin, Pelanggan \\
\hline Pra Kondisi & Admin Mengirim Pesan \\
\hline Paska Kondisi & Pelanggan mendapat pesan \\
\hline Deskripsi & Aktor mengrim pesan dan menerima pesan \\
\hline
\end{tabular}

\begin{tabular}{c|c}
\hline Aktor & Sistem \\
\hline 1. Memilih menu Pesan & 4. Mengeksekusi data masukan \\
2. Memilih jenis pengiriman & \\
3. Memilih tujuan & 5. Menampilkan data pesan \\
\hline & \\
\hline 6. & Melihat dan mengirimkan pesan ke \\
Pelanggan &
\end{tabular}

Proses pada tabel 5, Admin akan memilih menu pesan, lalu memilih jenis pengiriman seperti melalui email atau SMS Gateway. Setelah itu admin akan memilih tujuan pengiriman, dan pesan akan dikirim ke pelanggan.

Tabel 6. Skenario Use Case Point

\begin{tabular}{l|l}
\hline Use Case & Point \\
\hline Aktor & Pelanggan \\
\hline Pra Kondisi & Pelanggan melakukan tugas berpoint \\
\hline Paska Kondisi & Pelanggan mendapatkan tambahan point \\
\hline Deskripsi & Aktor mengelola data point \\
\hline Aktor & Sistem \\
\hline 1. Memilih menu point & $2 . \quad$ Tampil halaman point \\
\hline 3. Melihat hasil point pelanggan & 4. Menampilkan hasil point \\
\hline
\end{tabular}

Proses pada tabel 6, pelanggan akan masuk ke sistem, lalu sistem akan memberikan tugas untuk mendapatkan tambahan point. Lalu jika pelanggan melakukan tugas tersebut, pelanggan akan mendapatkan tambahan point. 
Tabel 7. Skenario Use Case Tukar Point

\begin{tabular}{|c|c|c|}
\hline Use Case & \multicolumn{2}{|c|}{ Tukar Point } \\
\hline Aktor & \multicolumn{2}{|c|}{ Pelanggan, Admin } \\
\hline Pra Kondisi & \multicolumn{2}{|c|}{ Pelanggan memilih hadiah point } \\
\hline Paska Kondisi & \multicolumn{2}{|c|}{ Admin menyetujui hadiah dan menukarkan hadiah } \\
\hline Deskripsi & \multicolumn{2}{|c|}{ Proses untuk menukarkan hadiah dari point } \\
\hline \multicolumn{2}{|l|}{ Aktor } & Sistem \\
\hline \multirow{2}{*}{\multicolumn{2}{|c|}{ 3. Memilih hadiah }} & 2. Tampil halaman point \\
\hline & & \\
\hline & & $\begin{array}{l}\text { 4. Memproses hadiah } \\
\text { 5. Mengurangi point }\end{array}$ \\
\hline 6. Menuk & hadiah & \\
\hline
\end{tabular}

Proses pada tabel 7, pelanggan akan memilih menu point, lalu sistem akan menampilkan hadiah yang bisa didapatkan oleh pelanggan berdasarkan point pelanggan. Kemudian pelanggan memilih hadiah tersebut, dan pelanggan harus datang ke toko untuk mengambil hadiah tersebut.

\section{HASIL DAN PEMBAHASAN}

Implementasi Halaman User Pelanggan

1. Halaman Login Pelanggan

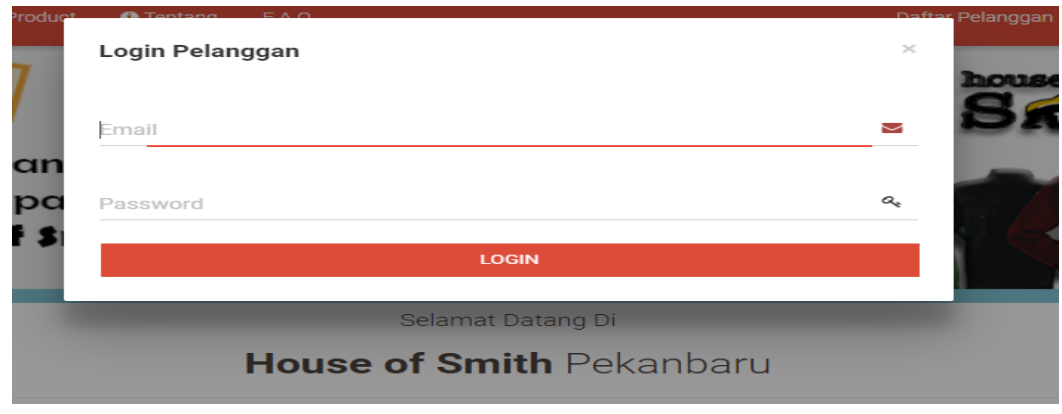

Gambar 2. Tampilan Halaman Login Pelanggan

Halaman login pelanggan merupakan halaman yang digunakan untuk login oleh pelanggan yang telah disetujui oleh admin.

2. Halaman Daftar Pelanggan

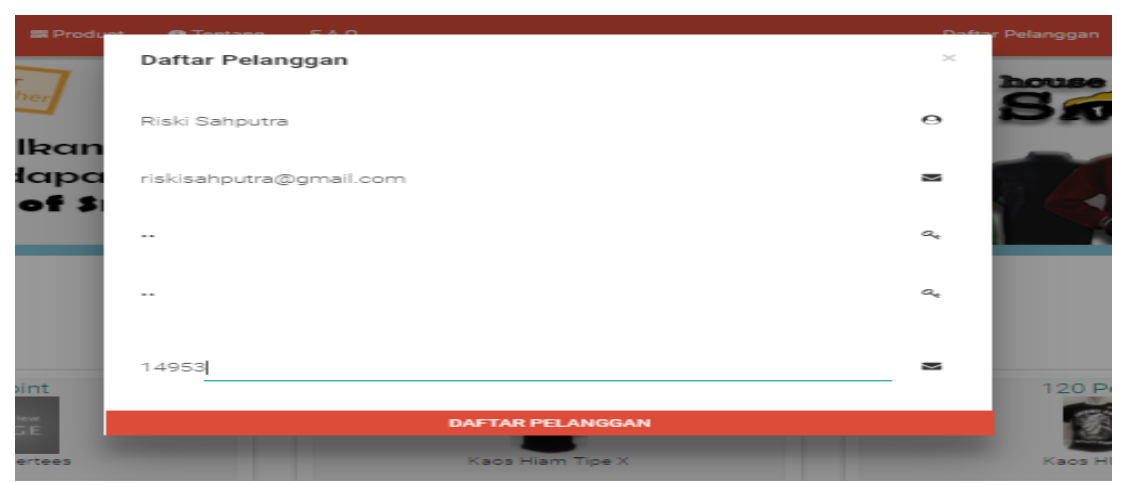

Gambar 3. Tampilan Halaman Daftar Pelanggan 
Halaman ini merupakan halaman yang digunakan calon pelanggan untuk mendaftar sebagai pelanggan di website House of Smith Pekanbaru.

3. Halaman Utama Pelanggan

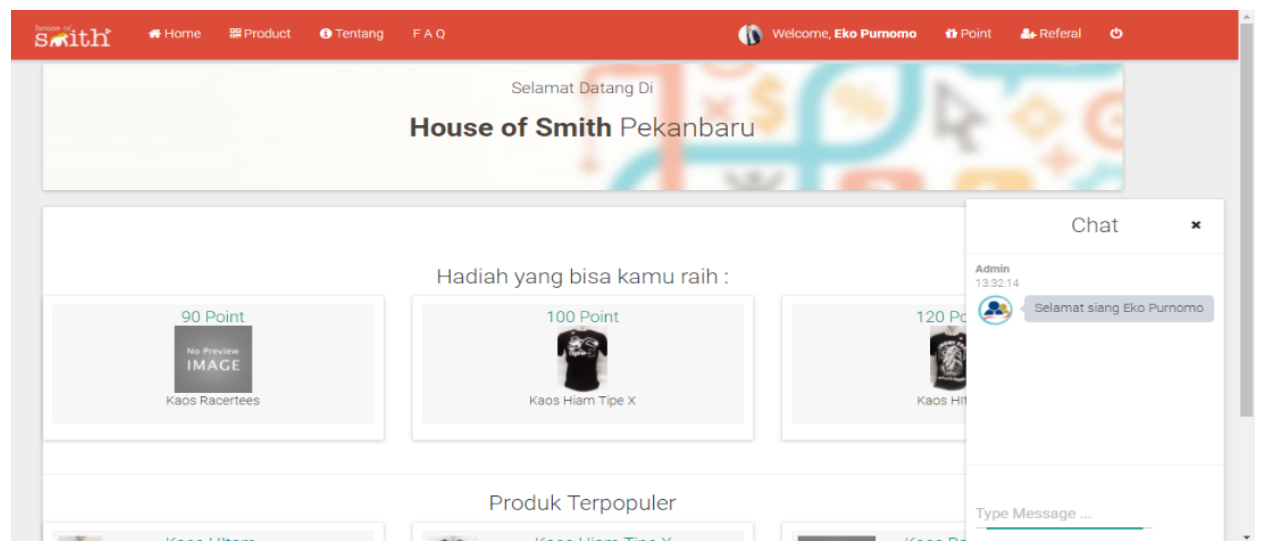

Gambar 4. Tampilan Halaman Utama Pelanggan

Halaman ini merupakan halaman utama saat pelanggan berhasil masuk ke website House of Smith Pekanbaru.

4. Halaman Product

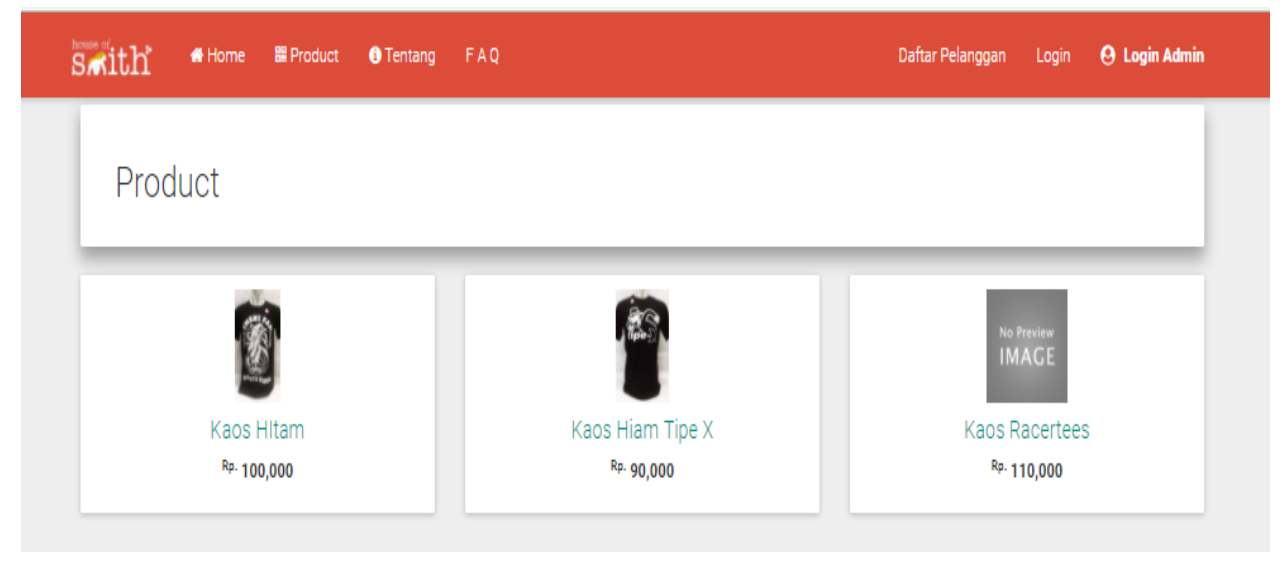

Gambar 5. Tampilan Data Product

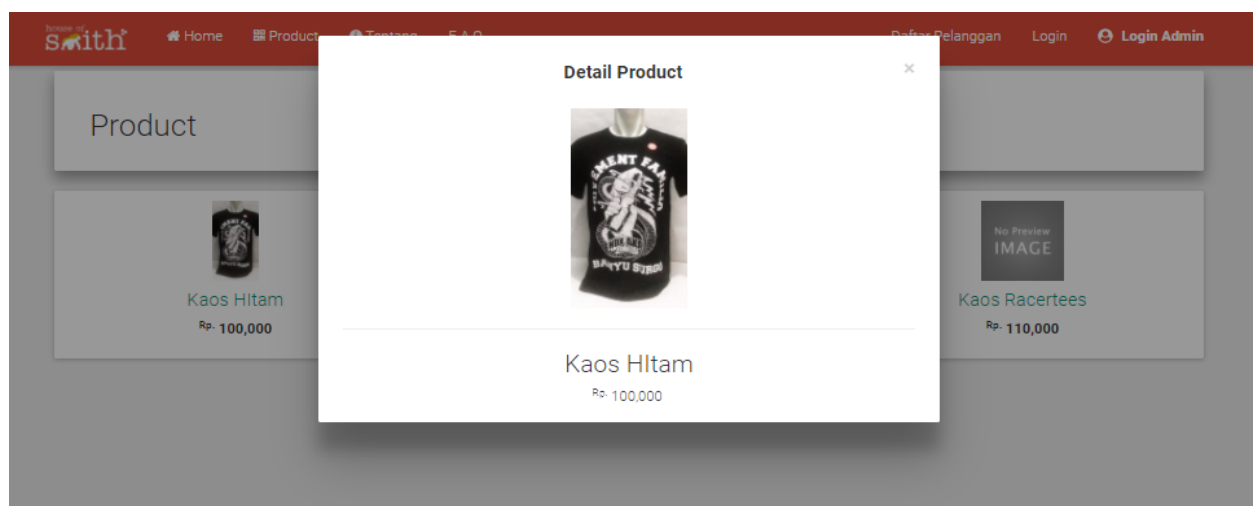

Gambar 6. Tampilan Detail Product 
Halaman ini merupakan halaman data product untuk pelanggan. Halaman ini difungsikan untuk mengenalkan product House of Smith Pekanbaru kepada pelanggan.

\section{Halaman FAQ}

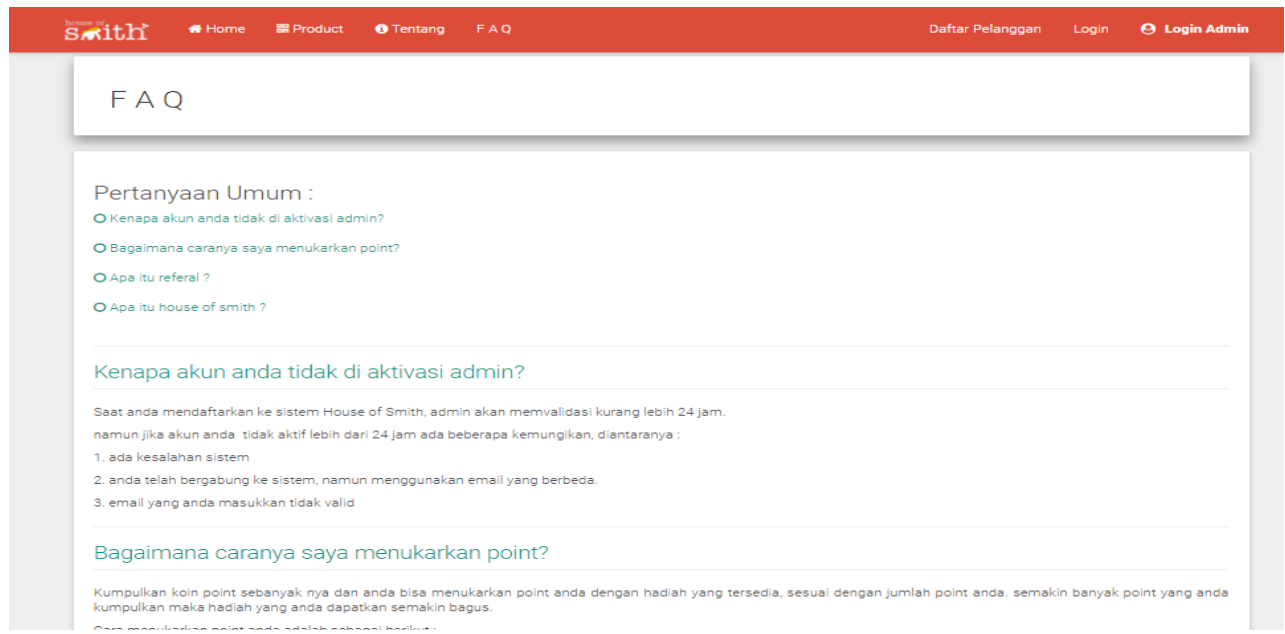

Gambar 7. Tampilan FAQ

Pada halaman ini pelanggan dapat melihat pertanyaan-pertanyaan yang sering diajukan oleh pelanggan lain.

6. Halaman Point

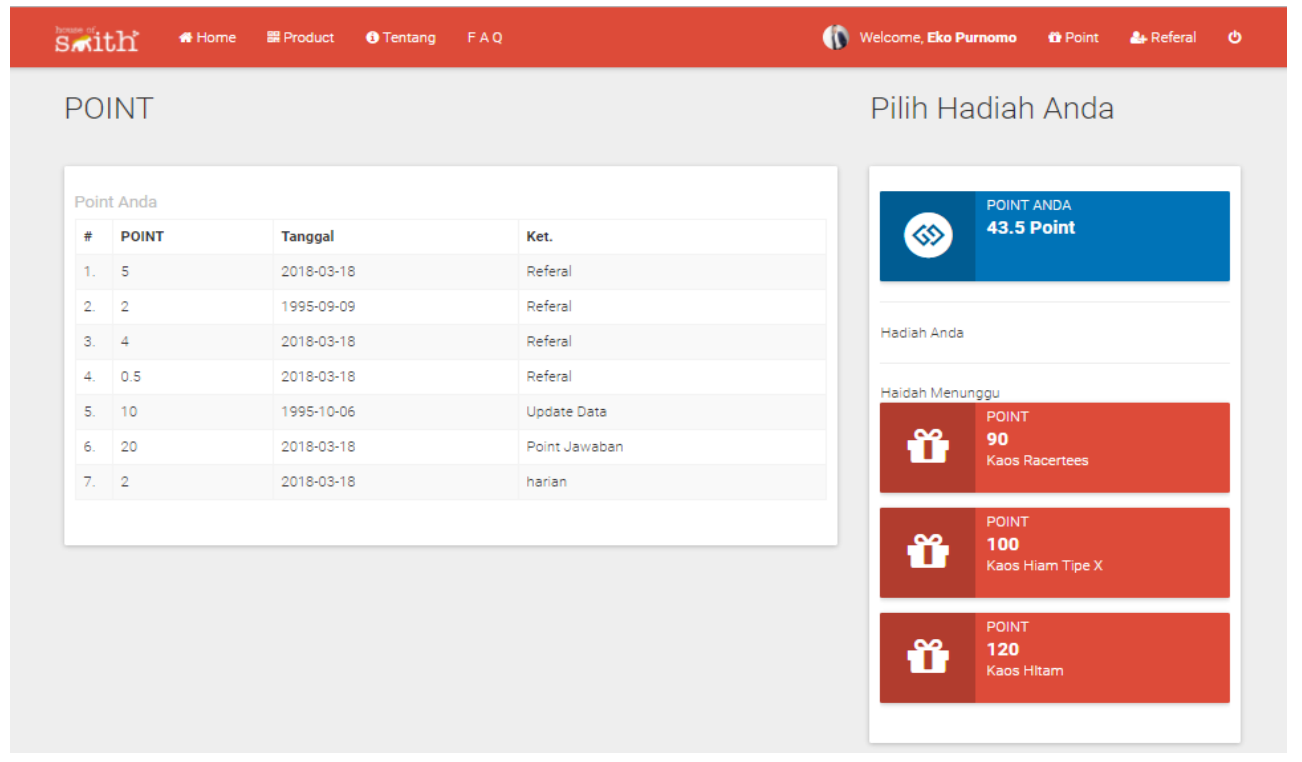

Gambar 8. Tampilan Point

Halaman ini halaman untuk melihat jumlah point pelanggan serta pelanggan akan dapat melihat hadiah yang bisa didapatkan dari point pelanggan tersebut.

7. Halaman Referal 


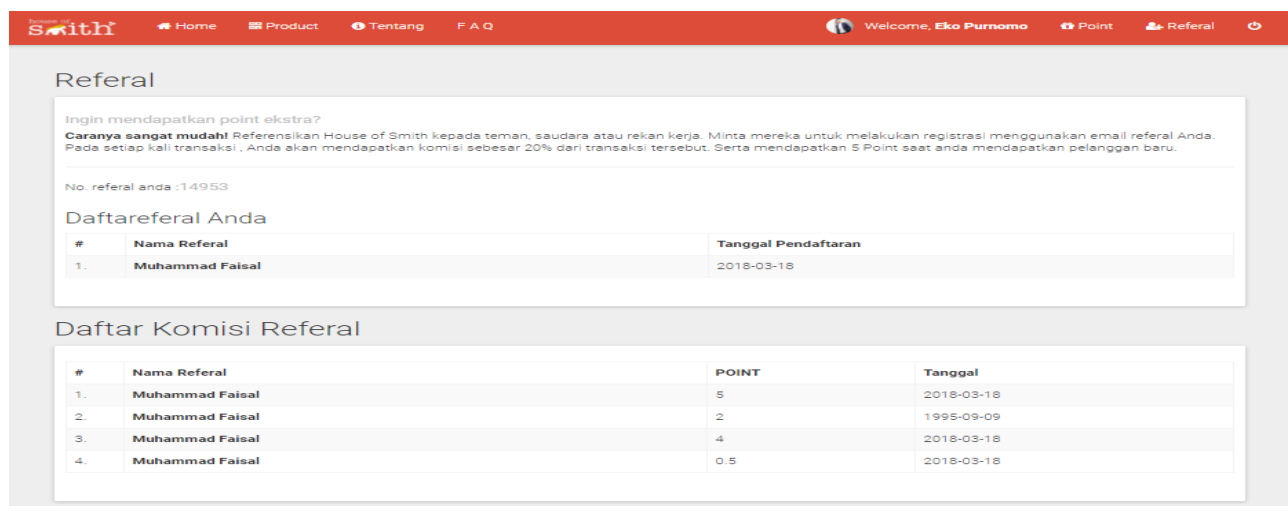

Gambar 9. Tampilan Referal

Halaman ini merupkan halaman untuk melihat hasil referal pelanggan.

8. Halaman Tukar Hadiah

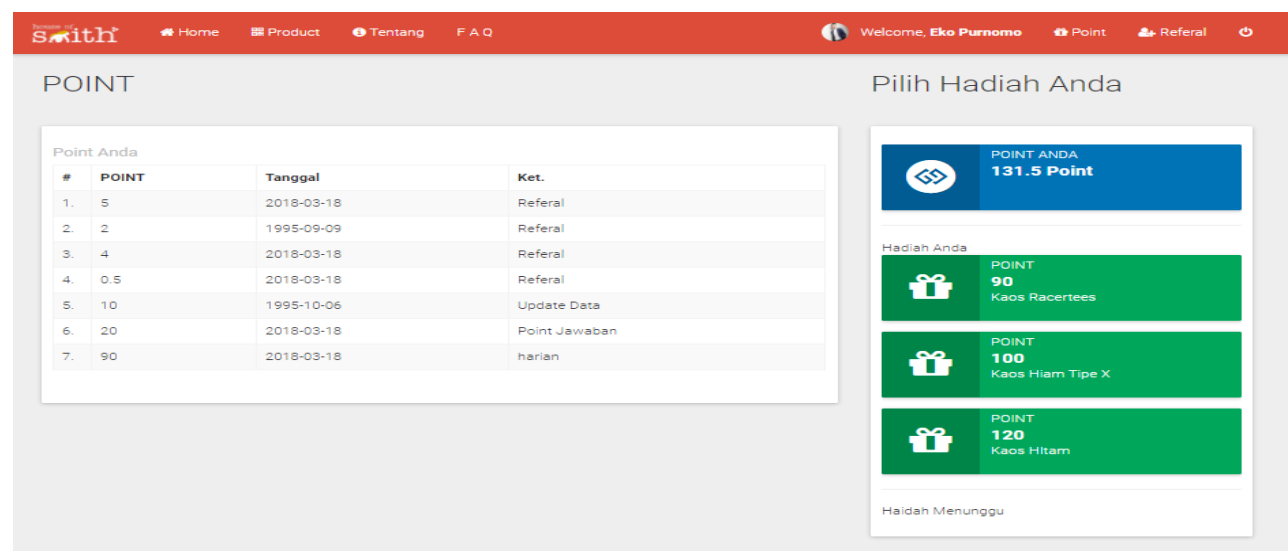

Gambar 10. Tampilan Tukar Hadiah Point

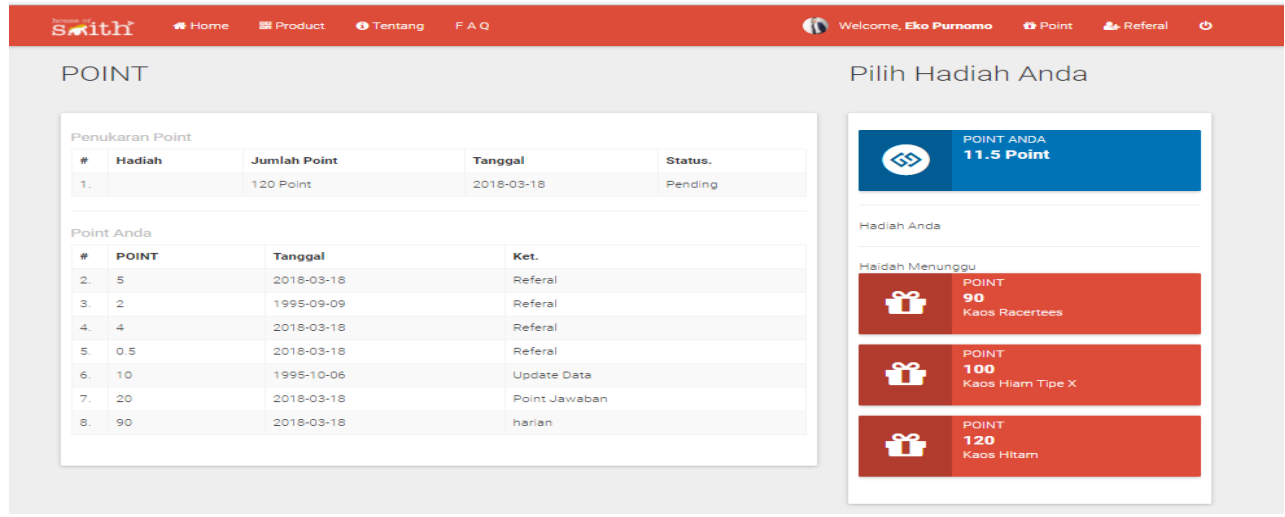

Gambar 11. Tampilan Setelah Tukar Hadiah Point

Halaman ini merupakan halaman untuk pelanggan menukarkan point mereka. Pada Gambar 10, pelanggan akan memilih hadiah yang akan mereka tukarkan. Setelah hadiah berhasil ditukarkan data akan disimpan dan dikirim ke admin, dan point pelanggan akan berkurang seperti pada Gambar 11. 


\section{KESIMPULAN}

Berdasarkan hasil penelitian dan pembahasan yang telah penulis lakukan maka dapat disimpulkan bahwa :

1. Website yang dibangun dapat membantu House of Smith Pekanbaru mendapatkan pelanggan baru dan mempertahankan pelanggan lama.

2. Website yang dibangun dapat memberikan feedback sesuai dengan kelompok pelanggan tertentu.

3. Website dapat dijadikan alat untuk berinteraksi dengan pelanggan secara maksimal dan memudahkan kinerja House of Smith Pekanbaru dalam berinteraksi dengan pelanggan.

\section{SARAN}

Adapun saran yang dapat diajukan dalam pengembangan dan perbaikan sistem ini adalah sebagai berikut:

1. Peneliti menyarankan agar menggunakan strategi bisnis yang lebih efektif dan efisien untuk menjaring pelanggan baru dan mempertahankan pelanggan lama.

2. Sistem yang dibuat belum mempertimbangkan keamanan data, untuk pengembangan selanjutnya diharapkan mempertimbangkan keamanan data untuk pertukaran data dan informasi dalam sistem.

\section{DAFTAR PUSTAKA}

[1] Nelly, Hudiarto, and R. Yudhika, "Perancangan E-Customer Relationship Management Pada PT Starsindo Logistics," ComTech, vol. 1, no. 2, pp. 449-460, 2010.

[2] I. G. So, "Analisis Perancangan Customer Relationship Management Berbasis Web Pada Pt Asp Jakarta Pendahuluan Latar Belakang Perumusan Masalah Tinjauan Teoritis," BINUS Bus. Rev., vol. 2, no. 1, pp. 100-114, 2011.

[3] K. Tsiptsis and A. Chorianopoulos, "Data Mining Techniques in CRM: Inside Customer Segmentation," in 1, 2009, p. 373.

[4] D. Nia, Kumaladewi., "Rancang Bangun Sistem Informasi Customer Relationship Management ( CRM ) Airport Special Assistance," Semin. Nas. Apl. Teknol. Inf. 2013, 2013.

[5] M. Rifai, A. Rosidi, and S. a Syahdan, "Relationship Management ) Pada Showroom Pt . Tropica Nucifera Industry Yogyakarta," J. Ilm. SISFOTENIKA, vol. 5, no. 1, pp. 1-12, 2015.

[6] P. Soepomo, M. Utam, and T. Yogyakarta, "Pembuatan Model Crm ( Customer Relationship Management ) Di PT . Mandar Utama Tiga Yogyakarta Dengan Metode Operational, Analytical Dan," vol. 3, pp. 49-59, 2015.

[7] D. Bhardwaj, "Building Data Mining Application for Customer Relationship Management," vol. 3, no. 1, pp. 33-37.

[8] V. R. Hananto, A. D. Churniawan, and A. P. Wardhanie, "Perancangan Analytical CRM untuk Mendukung Segmentasi Pelanggan di Institusi Pendidikan," J. Ilm. Teknol. Inf. Asia, vol. 11, no. 1, pp. 79-88, 2017.

[9] F. Buttle, "Customer Relationship Management: Concepts and Technologies," in 2, 2009, p. 523.

[10] D. C. and P. Smith, Emarketing Excellence: Planning and optimizing your digital marketing. 2013. 